\title{
Cardiac changes in pediatric liver transplant recipients: are they truly irreversible?
}

\author{
Florence Wong ${ }^{1}$
}

Received: 22 November 2015/Accepted: 21 January 2016/Published online: 16 February 2016

(c) Asian Pacific Association for the Study of the Liver 2016

\begin{abstract}
Abbreviations
LV Left ventricular

RAAS Renin-angiotensin-aldosterone system

TIPS Transjugular intrahepatic porto systemic shunt
\end{abstract}

Cardiac abnormalities are common in patients with liver cirrhosis. These can take the form of structural changes such as subtle increases in cardiac thickness or functional adaptation to systemic arterial vasodilatation such as a hyperdynamic circulation [1]. The term "cirrhotic cardiomyopathy" was coined in the late 1990s to describe the constellation of changes in the cardiovascular system found in patients with cirrhosis [2]. The working definition of this condition and the diagnostic criteria were formally proposed in 2005 [3]. The latter include systolic incompetence under conditions of stress, diastolic dysfunction and electrophysiological abnormalities, such as a prolonged QT interval, together with supportive findings, such as an increased left ventricular (LV) mass, or serological markers of cardiac dysfunction, such as elevated levels of troponin 1, atrial natriuretic peptide or b-type natriuretic peptide [4]. Since then, various expected or unexpected events observed in cirrhosis have been attributed to the presence of cirrhotic cardiomyopathy. These include sudden cardiac deaths following stressful procedures such as liver

Florence Wong

florence.wong@utoronto.ca

1 Division of Gastroenterology, Department of Medicine, Toronto General Hospital, University Health Network, University of Toronto, 200 Elizabeth Street, Toronto, ON M5G 2C4, Canada transplantation [5] or the insertion of a transjugular intrahepatic portosystemic shunt (TIPS) [6], the development of renal failure with [7] or without [8] an episode of spontaneous bacterial peritonitis, and the failure to eliminate ascites after TIPS insertion for the indication of refractory ascites [9].

Many theories have been proposed as to why the cirrhotic environment would be associated with abnormalities in cardiac structure and function. The haemodynamic changes of systemic vasodilatation in cirrhosis can lead to a reduction in the effective arterial blood volume and compensatory activation of various vasoconstrictor systems [10]; the end result is sodium and water retention as well as volume overload. All of these factors are known to cause cardiac changes, predisposing the cirrhotic patient to the development of cirrhotic cardiomyopathy. One of the activated vasoconstrictor systems is the renin-angiotensinaldosterone system (RAAS), components of which are known to stimulate cardiac growth and encourage cardiac remodelling. For example, angiotensin II has been shown to increase DNA synthesis in myocardial fibroblasts as well as promote protein synthesis in both myocytes and fibroblasts [11]. Angiotensin II also improves coronary artery permeability, thereby permitting growth factors to diffuse into the myocardium [12]. Excess sodium independent of volume overload can also lead to cardiac hypertrophy, and this appears to be mediated by excess aldosterone [13] as the use of an aldosterone antagonist can ameliorate the cardiac hypertrophy [14]. All of these will increase cardiac stiffness and promote diastolic dysfunction. In addition, the sympathetic overdrive in cirrhosis may cause asynergy and loss of efficiency of ventricular contraction and relaxation, thereby reducing cardiac function [15]. Finally, volume overload as seen in cirrhosis is also a known stimulus for cardiac remodelling [16]. 
Because the pathophysiology of cirrhotic cardiomyopathy is intricately linked to the hemodynamic abnormalities characteristic of cirrhosis, it is not surprising that cirrhotic cardiomyopathy is prevalent in cirrhosis. A postmortem analysis of 135 adult patients with cirrhosis revealed cardiac abnormalities in approximately one-third of patients [17]. It has been estimated that at least $50 \%$ of patients with liver cirrhosis who undergo liver transplantation have some signs of cardiac dysfunction [18], although many of these patients remain asymptomatic. There have been conflicting reports regarding the relationship between the degree of the cardiac dysfunction and severity of liver cirrhosis $[19,20]$. The cardiac abnormalities eventually seem to reverse with liver transplantation $[21,22]$, suggesting that the cirrhotic milieu is involved in the pathogenesis of the cardiac dysfunction observed in these patients.

Cirrhotic cardiomyopathy has also been reported in pediatric cirrhotic patients, although the prevalence seems a little unclear. In a study assessing two-dimensional echocardiogram parameters among 22 pediatric patients with biopsy-proven cirrhosis and 22 age- and gender-matched controls, there was no significant difference in LV ejection fraction, LV fractional shortening and LV diastolic dimensions [23]. A more recent report suggests that features of cirrhotic cardiomyopathy can be detected in approximately $20 \%$ of children [24]. Once again, the majority of the children remained asymptomatic. In this small cohort of children, the severity of the ascites was a most important risk factor for the development of cirrhotic cardiomyopathy. In another cohort of children with biliary atresia listed for liver transplantation, the prevalence of cirrhotic cardiomyopathy was significantly higher at more than $70 \%$. These children showed abnormal two-dimensional echocardiogram parameters including increased LV diastolic wall thickness, LV mass index and LV fractional shortening [25]. This apparent discrepancy can be explained by the additional effects of cholestasis on cardiac structure and function (Fig. 1). In an animal model of biliary fibrosis, mice fed with a diet rich in bile acids developed hyperdynamic LV contractility together with increased LV thickness [26]. The hearts of the mice on the bile acid-enriched diet showed activation of the genetic pathways that code for myocardial hypertrophy, as evidenced by a 20 -fold up-regulation of beta myosin heavy chain RNA. Therefore, these mice fatigued more easily on exercise and showed reduced tissue oxygen extraction, symptoms and signs that mimic patients with cardiac dysfunction. In addition, marked electrophysiological changes such as bradycardia and prolonged QT intervals were identified in the animals, features that have been identified in patients with cirrhotic cardiomyopathy.

Despite the greater incidence of cardiac abnormalities in situations of cholestasis, these changes appear to reverse

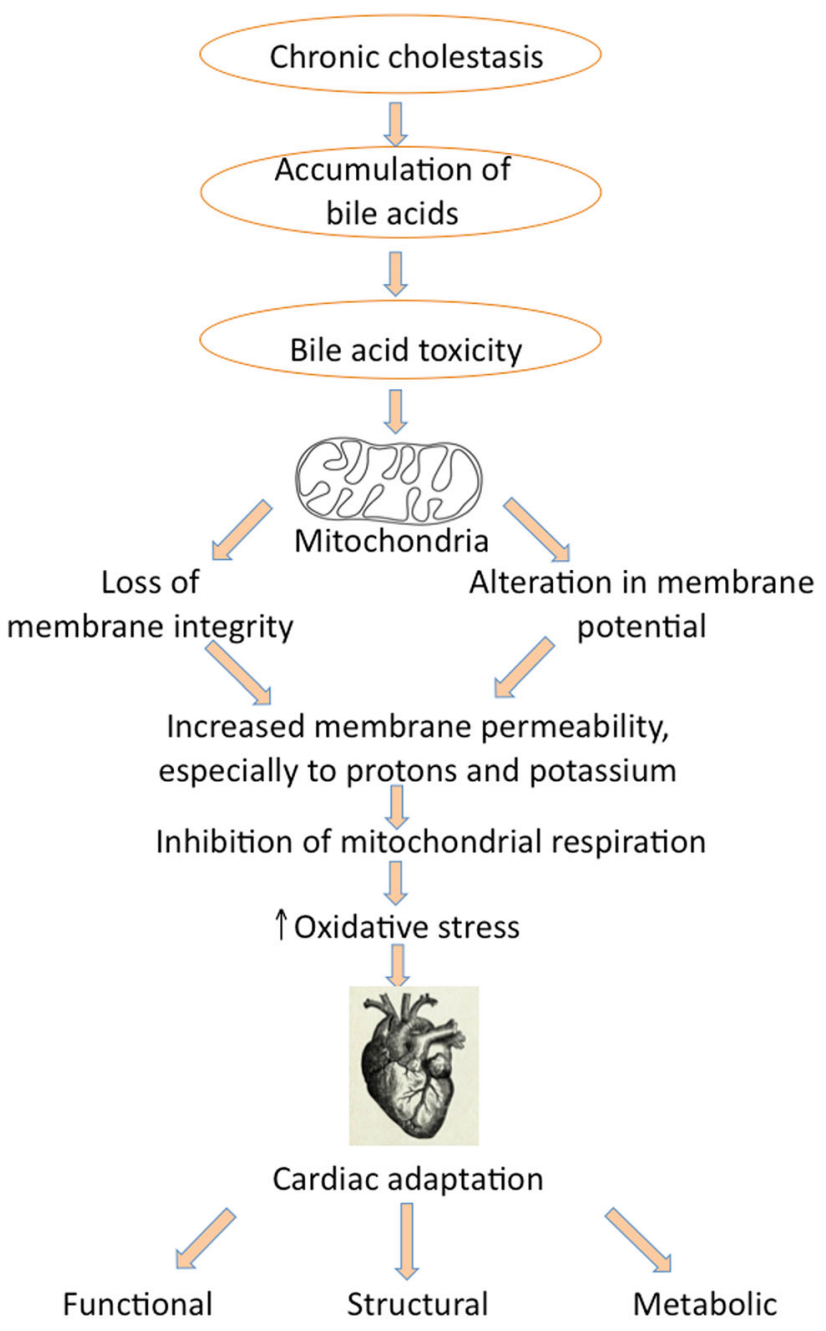

Fig. 1 Proposed mechanism of cholestasis-induced cardiac dysfunction (data obtained from Refs. [35, 36])

upon reduction of bile acid levels in animals fed normal chow after a period of a bile acid-enriched diet [27]. There was normalization of the two-dimensional echocardiogram parameters and electrophysiological abnormalities together with return of liver function back to normal. In addition, there was normalization of cardiac troponin-T2 as well as resolution of cardiac stress response at the RNA level, suggesting recovery of cardiac function. There was also a significant correlation between the extent of bile acid elevation in the serum and abnormalities in the cardiac physiological and molecular parameters. Therefore, it is not surprising to note that children with chronic cholestasis and cardiac abnormalities had significantly longer hospital stays and intensive care unit stays after liver transplantation [25], as these children were thought to be less able to cope with cardiac stresses during the operative and post-operative periods.

Liver transplantation is the procedure that removes the cirrhotic liver and corrects the portal hypertension. Therefore, abnormalities associated with cirrhosis will also 
resolve with liver transplantation. There have been many reports of reversal of cardiac changes associated with cirrhosis in both adults and children at a mean period ranging from 6 to 18 months after liver transplantation [21, 22, 27, 28]. Pre-transplant hyperdynamic circulation settles and cardiac hypertrophy resolves; prolonged QT intervals also disappear after liver transplantation. In this issue of the journal, there is another report on the cardiac changes in children pre- and post-liver transplantation [29]. Most of the children $(75 \%)$ had biliary atresia as the etiology of their cirrhosis. Therefore, similar to previous findings, the prevalence of abnormalities in various cardiac parameters was very high, ranging from 50 to $95 \%$. This is in keeping with the additional effects of severe cholestasis on cardiac structure and function [26]. However, unlike the previous reports, this study describes the lack of improvement of cardiac parameters after liver transplantation, although there was a gradual but non-significant reduction in the LV thickness and LV mass index, but both the systolic and diastolic functions did not change.

The next question is why the discrepancy? This may be related to the fact that cardiac changes in this study were re-evaluated at a very early phase, at 1-2 months and then again at 3-6 months after liver transplantation, whereas the previous studies reassessed their patients from at least 6 months post-liver transplantation [21, 22, 27, 28]; one study even delayed the cardiac studies till 18 months after liver transplantation [22]. In a study assessing the reversal of cardiac hypertrophy in patients with hypertension, the use of angiotensin receptor blocker was able to reduce the LV mass after 9 months of therapy [30]. The fact that a gradual reduction of LV mass was observed between the first and second post-transplant examinations would support the fact that had the authors allowed more time to elapse before repeating their measurements, a significant difference might have been observed.

The other possible explanation for the lack of reversal of cardiac changes in these children post-liver transplant may be related to the immuno-suppression used. Although it is not mentioned in the manuscript, most children receiving a solid organ transplant would have received tacrolimus as the primary immuno-suppressive agent [31]. A very rare but unique toxicity of tacrolimus in children is the development of cardiac hypertrophy [32], which can take the form of symmetrical or asymmetrical hypertrophy [33, 34]. The development of this toxicity seems to be linked to the serum levels of tacrolimus and this can start as early as 3 weeks post-liver transplantation [34]. We are not privileged to the serum levels of the immuno-suppressive agent that the children received from the report and therefore can only speculate the contribution this may have on the nonreversal of cardiac changes post-liver transplantation.
Despite all of these shortcomings, this study does bring out a few important points. First, children who mostly receive their liver transplant for cholestatic conditions may have a higher incidence of cardiac changes. Therefore, it is important that all children being assessed for liver transplantation should undergo careful cardiac assessment, as cardiac changes may negatively impact their hospital course for the liver transplant [24]. Second, cardiac changes that are present pre-operatively may persist for many months after the liver transplant. If cardiac changes continue beyond the first year, or if new symptoms develop, then it is imperative that the type of immuno-suppression used be re-evaluated.

This manuscript complies with the ethical requirements of the journal.

\section{References}

1. Wong F. Cirrhotic cardiomyopathy. Hepatol Int 2009;3:294-304.

2. Ma Z, Lee SS. Cirrhotic cardiomyopathy: getting to the heart of the matter. Hepatology 1996;24:451-459.

3. Møller S, Henriksen JH. Cardiovascular complications of cirrhosis. Gut 2008;57:268-278.

4. Licata A, Novo G, Colomba D, Tuttolomondo A, Galia M, Camma' C. Cardiac involvement in patients with cirrhosis: a focus on clinical features and diagnosis. J Cardiovasc Med 2016;17:26-36.

5. Rayes N, Bechstein WO, Keck H, Blumhardt G, Lohmann R, Neuhaus P. Causes of death after liver transplantation: an analysis of 41 cases in 382 patients. Zentralblatt Chir 1995;120:435-438.

6. Lebrec D, Giuily N, Hadenque A, Vilgrain V, Moreau R, Poynard T, Gadano A, et al. Transjugular intrahepatic portosystemic shunt: comparison with paracentesis in patients with cirrhosis and refractory ascites: a randomized trial. J Hepatol 1996;25:135-144.

7. Ruiz-del-Arbol L, Monescillo A, Arocena C, Valer P, Ginès $P$, Moreira V, Milicua JM, et al. Circulatory function and hepatorenal syndrome in cirrhosis. Hepatology 2005;42:439-447.

8. Krag A, Bendtsen F, Henriksen JH, Møller S. Low cardiac output predicts development of hepatorenal syndrome and survival in patients with cirrhosis and ascites. Gut 2010;59:105-110.

9. Rabie RN, Cazzaniga M, Salerno F, Wong F. The use of E/A ratio as a predictor of outcome in cirrhotic patients treated with transjugular intrahepatic portosystemic shunt. Am J Gastroenterol 2009:104:2458-2466.

10. Bolognesi M, Di Pascoli M, Verardo A, Gatta A. Splanchnic vasodilation and hyperdynamic circulatory syndrome in cirrhosis. World J Gastroenterol 2014;20:2555-2563.

11. Sadoshima J, Izumo S. Molecular characterization of angiotensin II-induced hypertrophy of cardiac myocytes and hyperplasia of cardiac fibroblasts. Critical role of the AT1 receptor subtype. Circ Res 1993;73:413-423.

12. Weber KT, Brilla CG. Pathological hypertrophy and the cardiac interstitium. Fibrosis and the renin-angiotensin-aldosterone system. Circulation 1991;83:1849-1865.

13. Williams JS, Williams GH, Jeunemaitre X, Hopkins PN, Conlin PR. Influence of dietary sodium on the renin-angiotensin-aldosterone system and prevalence of left ventricular hypertrophy by EKG criteria. J Hum Hypertens 2005;19:133-138. 
14. Lal A, Veinot JP, Leenen FH. Prevention of high salt diet-induced cardiac hypertrophy and fibrosis by spironolactone. Am J Hypertens 2003;16:319-323.

15. Brum PC, Kosek J, Patterson A, Bernstein D, Kobilka B. Abnormal cardiac function associated with sympathetic nervous system hyperactivity in mice. Am J Physiol Heart Circ Physiol 2002;283:H1838-H1845.

16. Cordaillat M, Reboul C, Gaillard V, Lartaud I, Jover B, Rugale C. Plasma volume and arterial stiffness in the cardiac alterations associated with long-term high sodium feeding in rats. Am J Hypertens 2011;24:451-457.

17. Ortiz-Olvera NX, Castellanos-Pallares G, Gómez-Jiménez LM, Cabrera-Muñoz ML, Méndez-Navarro J, Morán-Villota S, Dehesa-Violante M. Anatomical cardiac alterations in liver cirrhosis: an autopsy study. Ann Hepatol 2011;10:321-326.

18. Zardi EM, Abbate A, Zardi DM, Dobrina A, Margiotta D, Van Tassell BW, Afeltra A, et al. Cirrhotic cardiomyopathy. J Am Coll Cardiol 2010;56:539-549.

19. Merli M, Calicchia A, Ruffa A, Pellicori P, Riggio O, Giusto M, Gaudio C, et al. Cardiac dysfunction in cirrhosis is not associated with the severity of liver disease. Eur J Intern Med 2013;24:172-176.

20. Wong F, Girgrah N, Graba J, Allidina Y, Liu P, Blendis L. The cardiac response to exercise in cirrhosis. Gut 2001;49:268-275.

21. Torregrosa M, Aguadé S, Dos L, Segura R, Gónzalez A, Evangelista A, Castell $\mathrm{J}$, et al. Cardiac alterations in cirrhosis: reversibility after liver transplantation. J Hepatol 2005;42:68-74.

22. Chen Y, Chan AC, Chan SC, Chok SH, Sharr W, Fung J, Liu JH, et al. A detailed evaluation of cardiac function in cirrhotic patients and its alteration with or without liver transplantation. J Cardiol 2016;67:140-146.

23. Ozcay F, Tokel K, Varan B, Saygili A. Cardiac evaluation of pediatric liver transplantation candidates. Transpl Proc 2002;34: 2150-2152.

24. Celtik C, Durmaz O, Oner N, Yavuz T, Gökce S, Aydogan A, Nisli K, et al. Investigation of cardiomyopathy in children with cirrhotic and non-cirrhotic portal hypertension. J Pediatr Gastroenterol Nutr 2015;60:177-181.

25. Desai MS, Zainuer S, Kennedy C, Kearney D, Goss J, Karpen SJ. Cardiac structural and functional alterations in infants and children with biliary atresia, listed for liver transplantation. Gastroenterology 2011;141:1264-1272.

26. Desai MS, Shabier Z, Taylor M, Lam F, Thevananther S, Kosters A, Karpen SJ. Hypertrophic cardiomyopathy and dysregulation of cardiac energetics in a mouse model of biliary fibrosis. Hepatology 2010;51:2097-2107.

27. Finucci G, Lunardi F, Sacerdoti D, Volpin R, Bortoluzzi A, Bombonato G, Angeli P, et al. Q-T interval prolongation in liver cirrhosis. Reversibility after orthotopic liver transplantation. Jpn Heart J 1998;39:321-329.

28. Arikan C, Kilic M, Tumgor G, Levent E, Yuksekkaya HA, Yagci $\mathrm{RV}$, Aydogdu S. Impact of liver transplantation on rate-corrected QT interval and myocardial function in children with chronic liver disease. Pediatr Transpl 2009;13:300-306.

29. Khemakanok K, Khositseth A, Treepongkaruna S, Teeraratkul S, Pansrimangkorn W, Leelaudomlipi S, Bunmee U, et al. Cardiac abnormalities in cirrhotic children: pre- and post-liver transplantation. Hepatol Int 2015 [Epub ahead of print].

30. Solomon SD, Appelbaum E, Manning WJ, Verma A, Berglund T, Lukashevich V, Cherif Papst C, et al. Effect of the direct renin inhibitor aliskiren, the angiotensin receptor blocker losartan, or both on left ventricular mass in patients with hypertension and left ventricular hypertrophy. Circulation 2009;119:530-537.

31. Madan N, Arnon R, Arnon R. Evaluation of cardiac manifestations in pediatric liver transplant candidates. Pediatr Transpl 2012;16:318-328.

32. Dehghani SM, Haghighat M, Imanieh MH, Zahmatkeshan M, Borzooei M, Amoozegar H, Zamirian $M$, et al. Tacrolimus related hypertrophic cardiomyopathy in liver transplant recipients. Arch Iran Med 2010;13:116-119.

33. Atkison P, Joubert G, Barron A, Grant D, Paradis K, Seidman E, Wall W, et al. Hypertrophic cardiomyopathy associated with tacrolimus in paediatric transplant patients. Lancet 1995;345: 894-896.

34. Chang RK, McDiarmid SV, Alejos JC, Drant SE, Klitzner TS. Echocardiographic findings of hypertrophic cardiomyopathy in children after orthotopic liver transplantation. Pediatr Transpl 2001;5:187-191.

35. Ferreira M, Coxito PM, Sardão VA, Palmeira CM, Oliveira PJ. Bile acids are toxic for isolated cardiac mitochondria: a possible cause for hepatic-derived cardiomyopathies? Cardiovasc Toxicol 2005;5:63-73.

36. Desai MS, Eblimit Z, Thevananther S, Kosters A, Moore DD, Penny DJ, Karpen SJ. Cardiomyopathy reverses with recovery of liver injury, cholestasis and cholanemia in mouse model of biliary fibrosis. Liver Int 2015;35:1464-1477. 